\title{
A multi-purpose modular system for high-resolution microscopy at high hydrostatic pressure
}

\author{
Hugh Vass* ${ }^{1}$ S. Lucas Black*, ${ }^{1,2}$ Eva M. Herzig*, ${ }^{1}$ F. Bruce Ward ${ }^{* *},{ }^{2}$ Paul S. Clegg ${ }^{* *},{ }^{1}$ and Rosalind J. Allen**1 \\ ${ }^{1}$ SUPA, School of Physics and Astronomy, University of Edinburgh, \\ James Clerk Maxwell Building, The King's Buildings, Mayfield Road, Edinburgh EH9 3JZ, UK \\ ${ }^{2}$ Institute of Cell Biology, School of Biological Sciences, University of Edinburgh, \\ Darwin Building, Mayfield Road, Edinburgh EH9 3JR, UK
}

(Dated: October 30, 2018)

\begin{abstract}
We have developed a modular system for high-resolution microscopy at high hydrostatic pressure. The system consists of a pressurised cell of volume $\sim 100 \mu \mathrm{l}$, a temperature controlled holder, a ram and a piston. We have made each of these components in several versions which can be interchanged to allow a wide range of applications. Here, we report two pressure cells with pressure ranges 0.1$700 \mathrm{MPa}$ and $0.1-100 \mathrm{MPa}$, which can be combined with hollow or solid rams and pistons. Our system is designed to work with fluorescent samples (using a confocal or epifluorescence microscope), but also allows for transmitted light microscopy via the hollow ram and piston. The system allows precise control of pressure and temperature $\left[-20-70^{\circ} \mathrm{C}\right]$, as well as rapid pressure quenching. We demonstrate its performance and versatility with two applications: time-resolved imaging of colloidal phase transitions caused by pressure changes between $0.1 \mathrm{MPa}$ and $101 \mathrm{MPa}$, and imaging the growth of Escherichia coli bacteria at 50MPa. We also show that the isotropic-nematic phase transition of pentyl-cyanobiphenyl (5CB) liquid crystal provides a simple, convenient and accurate method for calibrating pressure in the range $0.1-200 \mathrm{MPa}$.
\end{abstract}

\section{INTRODUCTION}

Hydrostatic pressure is important in many research fields. The structural, physical and chemical properties of matter under pressure are of interest to physicists, chemists and materials scientists [1, 2, 3]. Hydrostatic pressure is also an important tool in elucidating the mechanisms underlying the assembly of protein and other macromolecular structures [4, 5, 6, 6], while pressure effects on cartilage and bone cells are physiologically and medically important [8]. From a technological point of view, moderate hydrostatic pressures $(\sim 200 \mathrm{MPa})$ have potential applications in protein manufacturing [9], while treatment with higher hydrostatic pressures $(>600 \mathrm{MPa})$ can be used to kill microorganisms in food sterilization [10] or surgical applications [11]. Finally, deep sea environments, which constitute a large part of the global biosphere, are exposed to hydrostatic pressures up to 101MPa. Understanding how biological organisms adapt to such pressures is of both fundamental scientific and biotechnological interest [12, 13, 14, 15].

In all of these contexts, optical microscopy is a powerful tool. Since depressurization before imaging constitutes a large and uncontrolled perturbation, it is a great advantage to be able to image a pressurized sample in situ at elevated pressure. However, microscope pressure cells are expensive and time-consuming to construct, and are often designed for a single application, making it difficult to use a particular system for multiple applications. In this paper, we report the development of a multipurpose microscope pressure-cell system, in which different mod-

*equal contribution, ** equal contribution ules can be interchanged to allow for different requirements in terms of microscopy technique, solvent tolerance, optical resolution and pressure range. The system can be used with a conventional epifluorescence, transmission or confocal microscope, has a large sample volume of $\sim 100 \mu$ l, is temperature controlled and is capable of rapid and well-controlled pressure ramping or quenching. Our focus is on biological and soft-matter physics applications in the pressure range $0.1-700 \mathrm{MPa}$.

A microscope pressure cell suitable for biological and soft-matter applications must have a large sample volume $(\sim 100 \mu \mathrm{l})$, in order to be able to observe "bulk-like" material or cellular behaviour. The pressure cell must also be compact and light enough to fit on a standard microscope stage. The cell must have optical windows which can sustain pressure. However, good optical resolution requires the working distance between the objective lens and the sample to be as small as possible. The window should therefore be as thin as possible and the window aperture as wide as possible to allow close approach of the objective to the window. One would also like to achieve well-controlled and rapid pressure quenching and temperature control. A number of pressure cells have been reported for imaging at moderate hydrostatic pressure; the properties of a representative sample of these are summarized in Table [. At higher pressures (several GPa), diamond anvil cells [16] are widely used; their small sample volume and thick diamond windows make them generally unsuitable for high resolution imaging of biological and soft matter samples under moderate pressures, although modified diamond anvil cells for imaging biological samples of small volume have been developed 17.

Although the cells listed in Table \ represent a wide range of capabilities, each is designed for a specific appli- 


\begin{tabular}{|c|c|c|c|c|c|c|}
\hline Ref. & Application & $\mid \begin{array}{c}\text { Sample } \\
\text { volume }\end{array}$ & \begin{tabular}{|l} 
Max \\
Pressure
\end{tabular} & Optical properties & Pressurization & Special features \\
\hline [17] & Microbiology & $0.1 \mu \mathrm{l}$ & $1.4 \mathrm{GPa}$ & $\begin{array}{l}\text { Diamond window } \\
250-600 \mu \mathrm{m} \text { thick, } 4 \mathrm{~mm} \text { diam. } \\
20 \times \text { objective }\end{array}$ & Gas-filled ram & $\begin{array}{l}\text { Diamond anvil cell } \\
\text { Temp range to } 300^{\circ} \mathrm{C}\end{array}$ \\
\hline 18 & Microbiology & $25 \mu \mathrm{l}$ & $700 \mathrm{MPa}$ & $\begin{array}{l}\text { Sapphire window } \\
5 \mathrm{~mm} \text { thick, } 10 \mathrm{~mm} \text { diam. } \\
20 \times \text { objective }\end{array}$ & Hand pump & \\
\hline 19 & Polymer physics & $\sim 300 \mu \mathrm{l}$ & $300 \mathrm{MPa}$ & $\begin{array}{l}\text { sapphire or diamond window } \\
\sim 2 \mathrm{~mm} \text { thick, } \sim 5 \mathrm{~mm} \text { diam, WD } 12 \mathrm{~mm} \\
10 \times \text { objective }\end{array}$ & Hand pump & $\begin{array}{l}\text { Polarization microscopy } \\
\text { Temp range }-40-270^{\circ} \mathrm{C}\end{array}$ \\
\hline 20 & \begin{tabular}{|l|} 
Liquid crystals \\
Polymer physics
\end{tabular} & & $300 \mathrm{MPa}$ & $\begin{array}{l}\text { Sapphire window } \\
5 \mathrm{~mm} \text { diam., WD } 3.5 \mathrm{~mm} \\
20 \times \text { objective }\end{array}$ & Hand pump & Temp range $20-250^{\circ} \mathrm{C}$ \\
\hline $21,22,23$ & Cell Biology & $3.5 \mu \mathrm{l}$ & $300 \mathrm{MPa}$ & $\begin{array}{l}\text { Sapphire window } \\
2.3 \mathrm{~mm} \text { thick, WD } 1.5 \mathrm{~mm} . \\
20 \times \text { or } 40 \times \text { objective } \\
\end{array}$ & Gasket & Fluorescence and transmitted \\
\hline 24 & Biophysics & $200 \mu \mathrm{l}$ & $200 \mathrm{MPa}$ & $\begin{array}{l}\text { Optical glass window } \\
1.5 \mathrm{~mm} \text { diam., WD } 6 \mathrm{~mm} \\
40 \times \text { objective }\end{array}$ & Hand pump & \\
\hline 25 & Cell biology & $100 \mu \mathrm{l}$ & $100 \mathrm{MPa}$ & $\begin{array}{l}\text { Pyrex glass window, } \\
2 \mathrm{~mm} \text { thick, } 2 \mathrm{~mm} \text { diam., WD } 3.8 \mathrm{~mm} \\
20 \times \text { or } 40 \times \text { objective }\end{array}$ & HPLC pump & $\begin{array}{l}\text { Continuous flow } \\
\text { Temp range } 2-80^{\circ} \mathrm{C}\end{array}$ \\
\hline 26 & Cell Biology & $75 \mu \mathrm{l}$ & $80 \mathrm{MPa}$ & $\begin{array}{l}\text { Strain-free glass } \\
1.75 \mathrm{~mm} \text { thick, } 3 \mathrm{~mm} \text { diam., WD } 2.3 \mathrm{~mm} \\
40 \mathrm{X} \text { objective }\end{array}$ & Hand pump & Polarization microscopy \\
\hline [27] & Biological cells & $\sim 1 \mu \mathrm{l}$ & $100 \mathrm{MPa}$ & $\begin{array}{l}\text { Image through wall of glass capillary } \\
0.34 \text { or } 0.5 \mathrm{~mm} \text { thickness } \\
10 \mathrm{X} \text { objective }\end{array}$ & Hand pump & $\begin{array}{l}\text { Fluorescence microscopy } \\
\text { Glass capillary tube }\end{array}$ \\
\hline 28,29 & 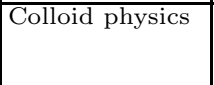 & $190 \mu \mathrm{l}$ & $40 \mathrm{MPa}$ & $\begin{array}{l}\text { Diamond window } \\
1 \mathrm{~mm} \text { thick, } 2.8 \mathrm{~mm} \text { diam, NA } 0.25 \\
10 \times \text { objective }\end{array}$ & HPLC pump & $\begin{array}{l}\text { Continuous flow } \\
\text { Temp range } 20-450^{\circ} \mathrm{C}\end{array}$ \\
\hline 30 & Cell Biology & $100 \mu \mathrm{l}$ & $15 \mathrm{MPa}$ & $\begin{array}{l}\text { Glass coverslip } \\
0.15 \mathrm{~mm} \text { thick, } 1 \mathrm{~mm} \text { diam. } \\
40 \times \text { objective }\end{array}$ & HPLC & $\begin{array}{l}\text { Continuous flow } \\
\text { Fluorescence and transmitted } \\
\text { Electrical stimulation of cells }\end{array}$ \\
\hline [31] & Cell Biology & $9 \mathrm{ml}$ & $10 \mathrm{MPa}$ & $\begin{array}{l}\text { Sapphire window } \\
2 \mathrm{~mm} \text { thick, } 30 \mathrm{~mm} \text { diam. } \\
40 \times \text { objective }\end{array}$ & HPLC flow cell & \\
\hline 32 & Cell Biology & $\sim 1 \mathrm{ml}$ & $7 \mathrm{MPa}$ & $\begin{array}{l}\text { Glass coverslip } \\
0.2 \mathrm{~mm} \text { thick, } 1 \mathrm{~mm} \text { diam. } \\
40 \times, 1.3 \mathrm{NA} \text { objective (fluorescence) }\end{array}$ & HPLC pump & Fluorescence and transmitted \\
\hline
\end{tabular}

TABLE I: Technical properties of a representative sample of high-pressure microscope cells for biological and soft-matter applications, as reported in the literature.

cation. Our aim was to develop a modular and multipurpose system, allowing for high-resolution high-pressure microscopy over a range of pressures up to $700 \mathrm{MPa}$, suitable for users in a variety of research fields. Given the expense and technical difficulty associated with the construction of a pressure cell, such a multi-purpose system should significantly facilitate high-pressure research. In Section $\amalg$ of this paper, we describe our system in detail. In Section III we discuss calibration and optical testing. In Sections [V] and $\mathrm{V}$, we demonstrate the system by presenting data on the kinetics of a pressure quench-induced colloidal phase transition and high-resolution imaging of bacteria growing under pressure. Finally, we present our conclusions in Section VI

\section{PRESSURE CELL DESIGN}

Figures 1(a) illustrates the design of our pressure cell system, a photograph of which is shown in Figure 1(b). Dimensions are given in Table II] The system consists of two basic parts: the pressure cell and the pressurizing ram. Each of these parts has an associated piston. The pressure cell, of diameter $35 \mathrm{~mm}$, contains the sample chamber [diameter $4.5 \mathrm{~mm}$ ], which has a window aperture

\begin{tabular}{|c|c|c|c|c|c|c|}
\hline \multicolumn{7}{|c|}{ Rams } \\
\hline & & & A & B & $\mathrm{C}$ & \\
\hline & lid ra & & 29.5 & 50.0 & $\overline{0.0}$ & \\
\hline & llow & $\mathrm{am}$ & 29.5 & 50.0 & 10.0 & \\
\hline & & Pres & ure $\mathrm{c}$ & & & \\
\hline & D & $\mathrm{E}$ & $\mathrm{F}$ & G & $\mathrm{H}$ & I \\
\hline Cell 1 & 13.5 & 3.0 & \begin{tabular}{|l|}
4.0 \\
\end{tabular} & 0.5 & 1.5 & 3.0 \\
\hline Cell 2 & 10.5 & 3.5 & 1.5 & 0.5 & 1.5 & 2.5 \\
\hline & Pre & ssure & cell & iston & & \\
\hline & & & & \begin{tabular}{|l}
$\mathrm{J}$ \\
\end{tabular} & & \\
\hline & $\overline{\text { Sol }}$ & & & 4.5 & & \\
\hline & $\mathrm{Ho}$ & 1 & ton & 4.5 & & \\
\hline
\end{tabular}

TABLE II: Dimensions of the rams, pressure cells and pistons. The letters refer to the illustration in Figure1, All dimensions are in millimetres.

of diameter $1.5 \mathrm{~mm}$. A piston of diameter $4.5 \mathrm{~mm}$ fits into the cell. The pressure cell is screwed into the ram, in such a way that the ram piston exerts pressure on the pressure-cell piston when hydraulic fluid is pumped into the ram. Brake fluid is used as the hydraulic fluid of choice, particularly for rapid quenching, due to its low compressibility and temperature-independent properties.

The pressure cell is made of TiMetal 550 titanium al- 
(a)

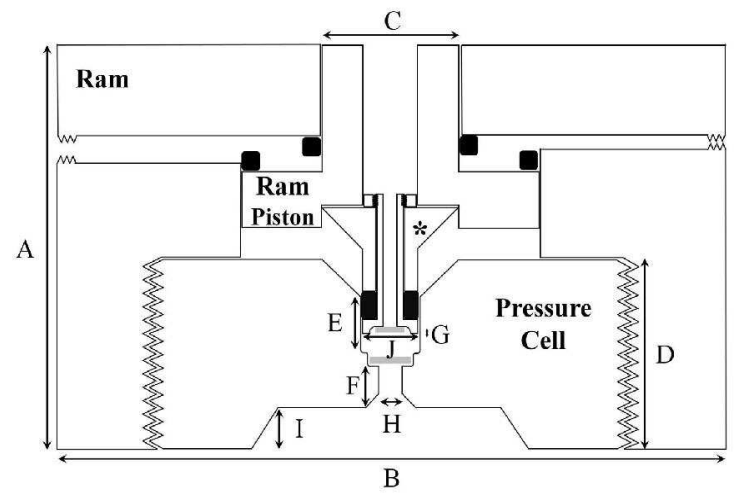

(b)

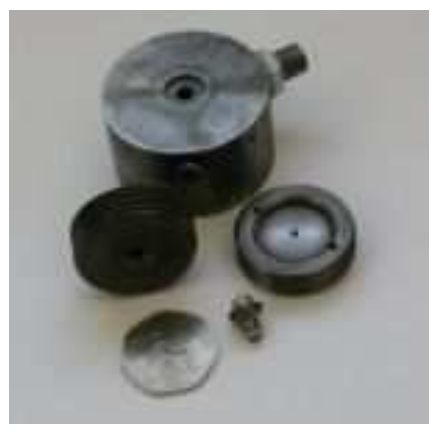

FIG. 1: (a): Cross-section of the pressure cell mounted in the pressurizing ram. The star denotes the pressure cell piston. The black squares indicate seals. The dimensions labelled by letters are listed in Table II (b): A photograph showing the hollow ram, pressure cells 1 and 2 and the hollow pressure cell piston, with coin (diameter $2.7 \mathrm{~cm}$ ) for size comparison.

loy, which is machined to shape and heat treated for maximum tensile strength. This heat treatment also causes the metal surface to darken, reducing the reflection of light inside the cell. The pressure cell window is made of either $0.5 \mathrm{~mm}$ thick type $2 \mathrm{~A}$ gem quality diamond (Element 6, Cuijk, The Netherlands) or $0.45 \mathrm{~mm}$ optical quality quartz (UQG Optics). The window is attached to the optically flat surface by a Poulter-type seal and fixed at $180^{\circ} \mathrm{C}$ with chemically resistant adhesive (MBond). The pressure cell piston is made of TiMetal 550, machined and heat treated as described above. Sealing rings are made of polytetrafluoroethylene (PTFE) for low pressure sealing (up to 200MPa) and phosphorbronze plus PTFE for high pressure sealing (up to $700 \mathrm{MPa}$ ). For transmitted light microscopy, we have made a version of the pressure cell piston which is hollow and contains a $0.5 \mathrm{~mm}$ thick diamond window, fixed using a Poulter-type seal as described above. Light can pass into the cell through this window, when used in conjunction with a hollow version of the ram piston. The ram is made of $\mathrm{w}-720$ tool steel (Böhler UK), fitted to standard hydraulic connectors, and the ram piston uses single or dual O-ring seals (solid and hollow versions respectively).

We have constructed multiple versions of both the ram and the pressure cell. These have different functionalities and can be combined in a modular fashion. The hollow version of the ram contains a hollow piston, and is suitable for transmitted light microscopy. An alternative, solid, ram contains instead a solid piston. The solid ram has a simpler and more rugged design, making it more suited to higher pressures. Pressure cell 1 is designed for pressures up to $700 \mathrm{MPa}$ and has a diamond window of thickness $0.5 \mathrm{~mm}$. This cell allows for a working distance of $4 \mathrm{~mm}$ and is compatible with a commercial $20 \times$ Extra Long Working Distance (ELWD) objective (Nikon; working distance: $8.1-7.0 \mathrm{~mm}, \mathrm{NA}: 0.45)$. Pressure cell 2 is designed for higher resolution at pressures up to $100 \mathrm{MPa}$. This cell has a quartz window of thickness $0.45 \mathrm{~mm}$, with a more open window surround, and can achieve a working distance of $1.4 \mathrm{~mm}$, making it compatible with a $60 \times$ ELWD objective (Nikon; working distance: 1.5-2.1mm, NA: 0.70). The pressure cells can be used in combination with either of two pressure cell pistons: a hollow piston containing a diamond window, which is suitable for transmitted light imaging, and a more rugged solid piston.

\section{CALIBRATION AND TESTING}

\section{A. Pressure calibration}

\section{Higher pressure (200-700MPa)}

In the higher pressure range (200-700MPa), the ruby fluorescence technique (R1 line) was used for calibration 33]. A tiny crystal of natural ruby was attached to the inside of the diamond window with transparent araldite and the cell was filled with water. Temperature was controlled at $26.0 \pm 0.1^{\circ} \mathrm{C}$. A neon bulb was used to provide a calibration reference line, in near coincidence with the R2 ruby line. A Coderg triple 800 spectrometer set for high resolution $\left(0.33 \mathrm{~cm}^{-1}\right)$, with steps of $0.125 \mathrm{~cm}^{-1}$, was used to obtain ruby spectra at different pressures, and the best fit to a Lorentzian lineshape was used to obtain the position of the R1 ruby line, relative to the neon reference, allowing the pressure inside the cell to be determined. A high resolution spectrometer is required because the magnitude of the R1 shift is very small. Results for pressure cell 1 are shown in Figure 2(a). The calibration was done with an Enarpac Bourdon gauge with a scale reading to $40 \mathrm{MPa}$, with the fluorescence wavelength shift taken as $7.68 \mathrm{~cm}^{-1} / \mathrm{GPa}$.

\section{Lower pressure $(<200 \mathrm{MPa})$}

In the lower pressure range (below 200MPa), a liquid crystal calibration method was used. This provides a remarkably simple yet accurate method of calibration which requires only accurate temperature control. The method involves observing the nematic to isotropic phase transition of pentyl-cyanobiphenyl $(5 \mathrm{CB})$ as the cell is 


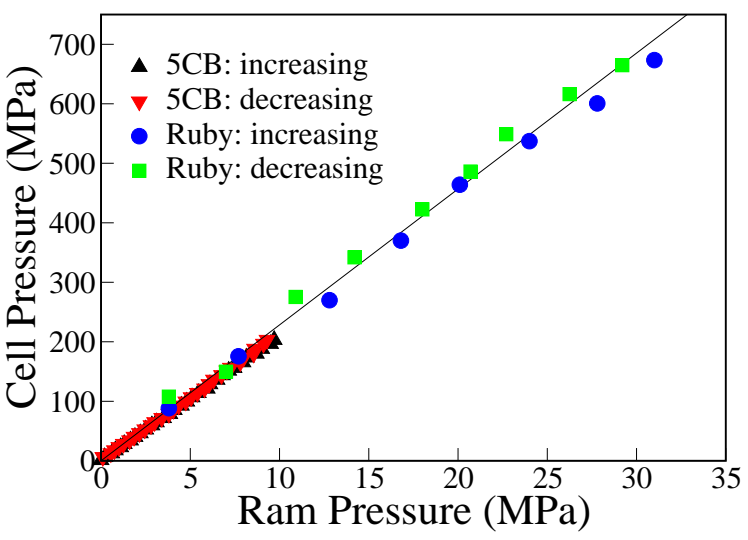

(a)

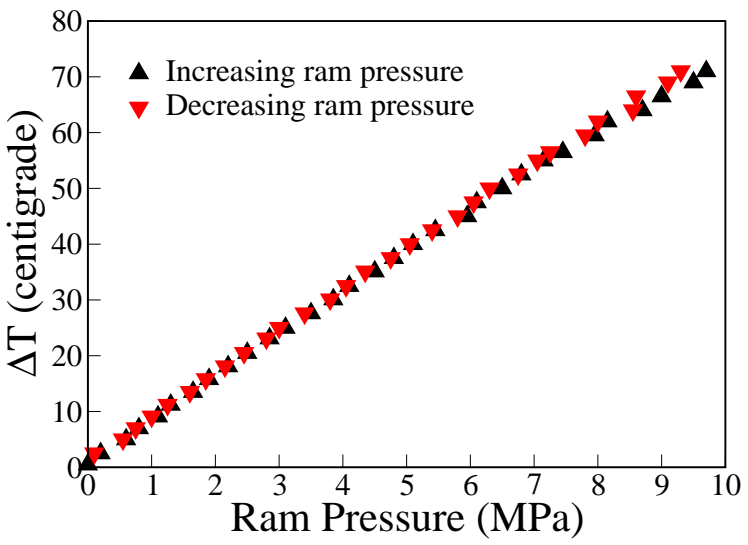

(b)

FIG. 2: Calibration data for pressure cell 1 with the hollow ram. (a): Cell pressure as a function of ram pressure for the ruby calibration and for the $5 \mathrm{CB}$ calibration (using the data from panel (b)). The solid line indicates the "ideal" results if the seals were $100 \%$ efficient and frictionless (calculated from the ratio of piston areas, assuming the ram pressure gauge to be accurate). Blue circles represent ruby data collected for increasing pressure, while green squares denote ruby data for decreasing pressure. Upward black triangles: $5 \mathrm{CB}$ data for increasing ram pressure; downward red triangles: $5 \mathrm{CB}$ data for decreasing ram pressure.(b): $5 \mathrm{CB}$ transition temperature as a function of ram pressure $(\Delta T$ refers to the temperature above the ambient pressure transition). Symbols are as in panel (a).

heated in stages through the transition into the isotropic phase. The transition pressure in the cell can then be calculated from the formula derived by Shashidhar and Ventkatesh [34] for 5CB:

$$
\Delta T=40.3 P-2.64 P^{2}
$$

where $\Delta T$ is the temperature above the ambient pressure transition temperature (in centigrade) and $\mathrm{P}$ is in kbar $(1 \mathrm{kbar}=101 \mathrm{MPa})$. Ram pressure is then gradually applied until the nematic phase is restored. By slowly reducing the ram pressure until the transition reverses, a measurement of the hysteresis of the cell at that pressure is obtained.

To observe the transition, about 2 to $3 \mathrm{~mm}$ depth of neat $5 \mathrm{CB}$ was placed in the cell and sealed with the light transmitting (hollow) pressure cell piston. A small amount of laser light passed through the cell and was observed on a screen. As pressure was applied, the laser spot shimmered just before the transition before being abruptly extinguished at the transition. After about 30 seconds a much weaker spot appeared on the screen with a polarisation generally different to the laser polarisation. On slowly releasing the ram pressure, the spot shimmered and then became much brighter as the transition reversed.

Although a laser was used in this calibration, it is not essential: the transition can be observed quite easily with ordinary light. As the cell pressure is derived directly from the temperature, a cheap low accuracy Bourdon gauge is sufficient for the ram pressure measurement, as long as the calibration curve is re-measured for each gauge.

Figure 2(b) shows a 5CB calibration of pressure cell 1. The ram pressure was measured with a small $10 \mathrm{MPa}$ R.S. Bourdon gauge. Figure 2 (a) (triangles) shows the same data, with the vertical axis translated into the cell pressure using Eq.(11). The solid line shows the expected pressure in the cell if the seals were $100 \%$ efficient and had zero friction. Both the $5 \mathrm{CB}$ and ruby calibrations in Figure2(a) show straight lines with very little hysteresis. The gradient of the line for the $5 \mathrm{CB}$ calibration is slightly lower than that for the ruby calibration, suggesting that the $10 \mathrm{MPa}$ gauge was slightly overestimating the ram pressure with respect to the $40 \mathrm{MPa}$ gauge. This was later confirmed in a separate measurement. We note that the $5 \mathrm{CB}$ calibration method could be extended to higher pressures for pressure cells which can withstand very high temperatures.

\section{B. Optical resolution}

To evaluate the optical resolution of our two pressure cells, we imaged $3 \mu \mathrm{m}$ fluorescent beads (Sigma-Aldrich) in a Nikon/Bio-Rad confocal microscope with a $488 \mathrm{~nm}$ laser. Figure 3 shows horizontal (a and b) and vertical (c and d) section images of a single bead, averaged over 8 frames and corrected for the sample medium [35]. While we are able to resolve single beads in both pressure cells, significantly better resolution is achieved with cell 2 .

\section{APPLICATION 1: COLLOIDAL PHASE TRANSITION KINETICS}

Hydrostatic pressure can be used in colloid science to modify interactions, change the relative composition of multi-component samples (if the components have different compressibilities) and to reach new nonequilibrium states by rapid quenching. For example, the effect of pressure on hydrophobic interactions has been explored experimentally for proteins [36] and polymers 
(a)

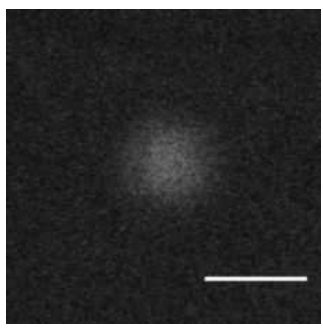

(c)

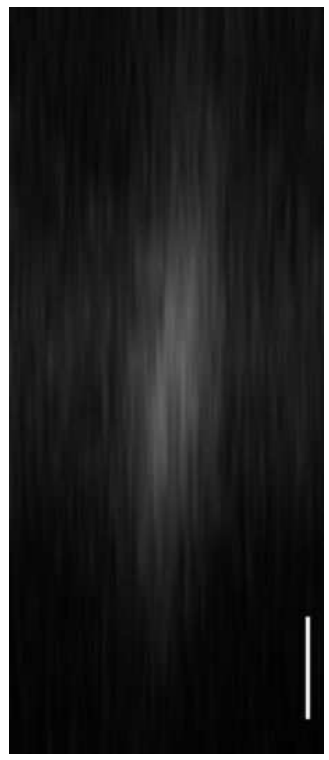

(b)
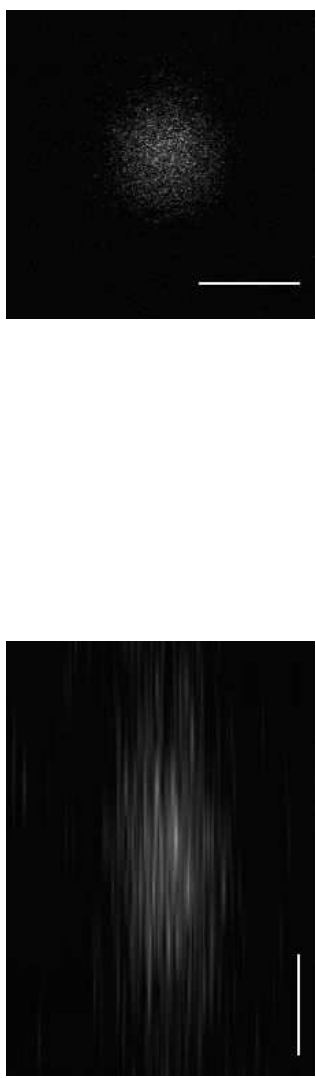

slow and rapid pressure quenches.

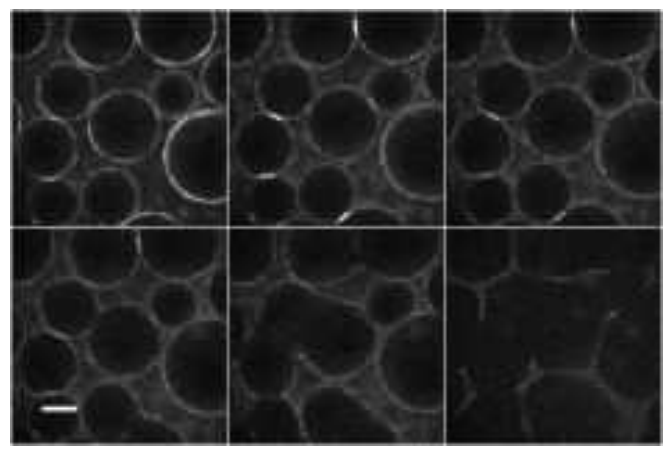

FIG. 4: Fluorescence confocal microscopy images of a phase transition from immiscible to miscible states by applying a slow pressure ramp from $0.1 \mathrm{MPa}$ to $101 \mathrm{MPa}$ at a temperature of $37^{\circ} \mathrm{C}$. The sample is an off-critical composition mixture of water and 2,6-lutidine emulsified by interfacial silica particles (volume fraction $0.5 \%$ ). The frames are recorded every 0.5 seconds; the scale bar is $100 \mu \mathrm{m}$.

Figure 4 shows a series of images of a binary fluid of water and 2,6-lutidine containing colloidal silica particles, as it undergoes a slow change in pressure from $0.1 \mathrm{MPa}$ to $101 \mathrm{MPa}$. The interfaces between the liquid phases are stabilized by the colloidal silica (this is a particlestabilized emulsion [45]). The silica is dyed using the fluorescent dye FITC and a small fraction of the silica particles are dispersed in the continuous phase of the emulsion. The use of fluorescence facilitates imaging deeper into the sample. At the start of the experiment the binary fluid sample is under conditions $\left(37^{\circ} \mathrm{C}\right.$, atmospheric pressure) where the two liquids are demixed. On increasing the pressure the liquids begin to remix - reducing the interfacial tension and hence releasing some of the particles trapped at the interface. The particles are pushed into close contact as the emulsion is destroyed, resulting in some residual clustering in the final frame, even though by this frame the liquids are completely demixed.

We next demonstrate the use of pressure cell 1 for a rapid pressure quench experiment on the water, 2,6lutidine, colloidal silica system. Here, we start the experiment in the single-fluid region of the phase diagram where the two liquids are mixed $\left(101 \mathrm{MPa}\right.$ and $35^{\circ} \mathrm{C}$, achieved by first pressurising then warming the sample). At this temperature and at atmospheric pressure the liquids would be in the demixed, two-fluid phase. We can therefore observe the demixing transition by rapidly releasing the pressure; this is achieved by dumping the pressurising brake fluid out of the ram through a solenoid valve.

The confocal microscopy images captured during the pressure quench experiment are shown as a time sequence in Figure 5. Since the images are formed by scanning a laser, time progresses both between frames (left to right) and from the top to the bottom of a frame. The first frame in Figure 5 shows a dispersion of particles in the 


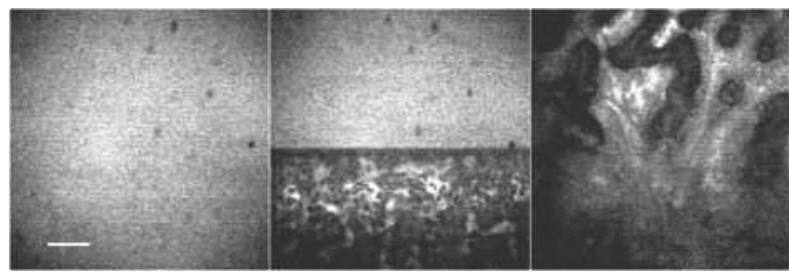

FIG. 5: Fluorescence confocal microscopy images of phase separation induced by a pressure quench. The sample is a dispersion of fluorescent silica colloids (volume fraction $0.5 \%$ ) in critical composition water-2,6-lutidine. Time increases from left to right in this series of images; the time separation between images is 1.034 seconds; the scale bar is $100 \mu \mathrm{m}$. Each image is $512 \times 512$ pixels and is produced by rastering a laser at 500 lines per second. At the start of the experiment the system is mixed: the pressure release causes a demixing transition.

single-fluid phase. The brake fluid is released while the laser is scanning the second frame and this induces a rapid phase separation: a dramatic change in the sample properties occurs over the scanning of five horizontal lines. By the third frame, the phase separation is well developed; the colloidal particles partition into one of the phases which appears brighter than the other. This series of images can be used to estimate the speed of the pressure quench: since the phase transition occurs within the scanning of five lines (at 500 lines per second), we estimate that the quench occurs in $10 \mathrm{~ms}$. We note that the sudden change in pressure under adiabatic conditions results in a concomitant change in the temperature [4] we verified that this change in temperature did not itself cause a phase transition.

\section{APPLICATION 2: BACTERIAL GROWTH UNDER PRESSURE}

Hydrostatic pressure is of interest in microbiology in several contexts. Understanding how deep sea microorganisms have evolved to tolerate and even require pressure [12, 46] has potential applications in biotechnology as well as marine ecology. Applying pressure to non-pressure-adapted microorganisms is also of interest, both as a means of food sterilisation [10, 47, 48] and in the general context of microbial stress response $[14,49$, 50, 51, 52]. In all these areas, the ability to image microorganisms in a pressurised microscope cell can provide powerful insights. For example, microscopy can reveal pressure effects on DNA configuration [47, 48] or protein localisation [53] within the cell. A microscopic approach also allows one to detect heterogeneity among the cellular population (which is believed to be an important factor in survival of environmental stresses [54, 55$]$ ), and to measure single-cell properties such as swimming speeds [56].

Here, we demonstrate that our system can be used (a)

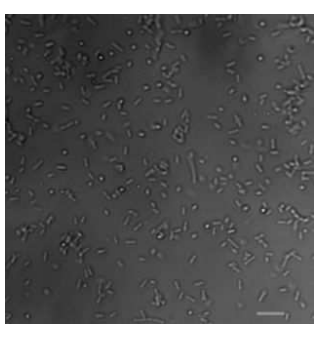

(b)

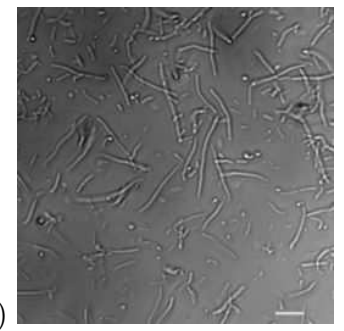

(c)

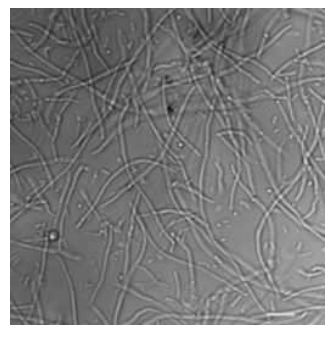

FIG. 6: E. coli MG1655 growing in pressure cell 2 at $37^{\circ} \mathrm{C}$ at $50 \mathrm{MPa}$ (a) 120 minutes, (b) 620 minutes, (c) 20 hours after pressurisation. The scale bar is $10 \mu \mathrm{m}$. In these experiments, cells were first grown in a flask in Luria Bertani (LB) medium supplemented with $25 \mathrm{mM}$ glucose for 2 hours at $0.1 \mathrm{MPa}$ and $37^{\circ} \mathrm{C}$. The culture was then loaded into pressure cell 2 and left for 30 minutes to allow cells to attach to the window, before being poured off and replaced by fresh LB-glucose medium. The pressure cell was then sealed using the hollow piston and pressurised. Bright-field images were captured every 20 minutes on an inverted Nikon Ti-U microscope with a Sony CoolSnap camera using a $60 \times$ ELWD objective (NA 0.70). (a)

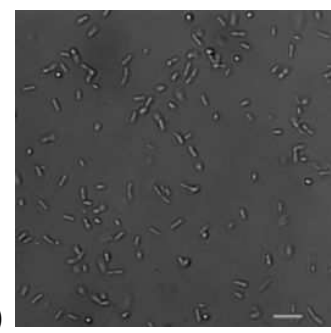

(c)

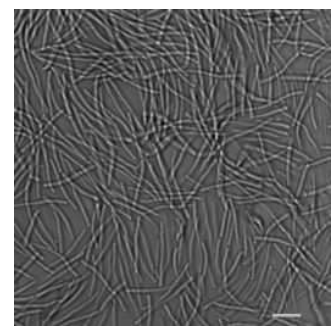

(b)

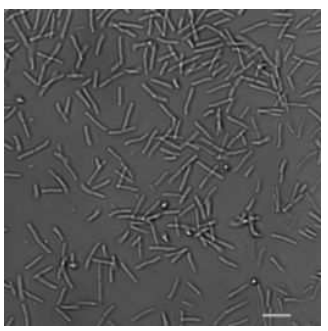

(d)

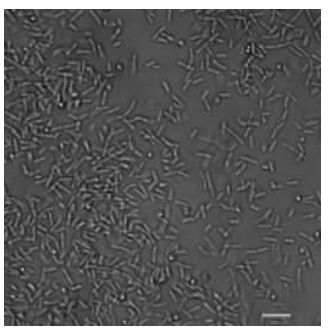

FIG. 7: E. coli BW25113 $\Delta$ lon growing in pressure cell 2 at $37^{\circ} \mathrm{C}$ at $50 \mathrm{MPa}$ (a) 40 minutes, (b) 200 minutes, (c) 400 minutes after pressurisation, and (d) the same strain growing at at $37^{\circ} \mathrm{C}$ and $0.1 \mathrm{MPa}$, imaged 120 minutes after inoculation. The scale bar represents $10 \mu \mathrm{m}$. These experiments were performed as described in the caption to Figure 6 Strain BW25113 $\triangle$ lon was obtained from the Keio collection of deletion mutants [57]. 
to monitor pressure-associated morphological changes in the bacterium Escherichia coli. E. coli is a non-pressureadapted organism whose cells are rod-shaped and of typical size $1 \times 2 \mu \mathrm{m}$ when growing exponentially at atmospheric pressure. The morphological response of $E$. coli to pressure is well documented. The details are strain-dependent, but a general picture is that when exposed to pressures up to $\sim 25 \mathrm{MPa}, E$. coli cells continue to grow and divide, but become somewhat elongated compared to those grown at atmospheric pressure [58, 59, 60]. At higher pressures, in the range 30-50MPa, cell division is inhibited, leading to filamentous growth [49, 53, 58, 59, 61], while growth is abolished altogether above $\sim 60 \mathrm{MPa}[49,53,58]$. Exposure to pressures above $\sim 150 \mathrm{MPa}$ leads to cell death: microscopic studies of $E$. coli after short-term exposure to such pressures have reported filamentation 62], aggregation of cytoplasmic proteins [47, 48] and nucleoid condensation [47, 48].

Here, we present transmitted light images of $E$. coli cells growing at $50 \mathrm{MPa}$, obtained using pressure cell 2 on an inverted Nikon Ti-U microscope with a $60 \times$ ELWD objective. We compare the behaviour of two E. coli strains: the wild-type strain MG1655 and strain BW25113 $\Delta$ lon [57] which is unable to produce the Lon protease enzyme.

Figure 6]shows E. coli MG1655 cells growing at 50MPa, 120 minutes (a), 620 minutes (b) and 20 hours (c) after pressurisation. The experimental protocol is given in the caption. Filamentation is clearly apparent (whereas the same strain grown in the pressure cell at $0.1 \mathrm{MPa}$ shows no filamentation; data not shown). Interestingly, the population is heterogeneous: there is variability in length among those cells that do filament and some cells apparently do not filament at all. We have observed motility of some of these non-filamented cells even after 20 hours growth at 50MPa. A distribution in lengths among filamentous cells grown under pressure has been noted before [59], but to our knowledge this variability has not been studied in detail.

Figure 7 shows equivalent images for the mutant BW25113 $\Delta$ lon [57], which is unable to produce the Lon protease. This strain, like MG1655, is able to divide normally when grown at $0.1 \mathrm{MPa}$, but produces filaments when grown at 50MPa. However, in contrast to MG1655, the lon mutant population appears to filament homogeneously, with fewer unfilamented cells being visible. Previous work by Aertsen and Michiels has shown that lon mutants display hyperfilamentation after brief periods of pressurisation at $100 \mathrm{MPa}$, and that this is due to activation of the SOS response pathway [51, 60, 63]. Interestingly, however, previous work characterising changes in the E. coli protein [49] and mRNA [64] composition during growth at $\sim 50 \mathrm{MPa}$ has not shown activation of the SOS pathway. We plan to carry out a more detailed study of the factors governing filamentation at 50MPa in BW25113 lon versus MG1655 in future work.

\section{CONCLUSIONS}

In this paper, we have described a microscope pressure cell system with a modular design, in which parts can be interchanged to allow for a wide range of applications. Our system consists of a pressurized cell and piston, a ram with associated piston, and a temperaturecontrolled holder. We have designed two versions of the pressurized cell, suitable for pressures in the ranges 0.1 $700 \mathrm{MPa}$ (cell 1) and 0.1-200MPa (cell 2). We have also developed two versions of the pressure cell piston, one hollow, to allow for transmitted light imaging, and the other solid and more rugged in design, and the ram has been constructed in both hollow and solid versions. The system was calibrated using the ruby fluorescence technique for pressures in the range $200-700 \mathrm{MPa}$, and using a method based on the isotropic-nematic transition of the liquid crystal 5CB in the pressure range 0.1-200MPa. The latter proved a very simple and convenient calibration method.

We have demonstrated our pressure cell system for two different applications. Our first application was in colloid science. Here, we used pressure cell 1 to image phase separation in a binary fluid in which the fluid-fluid interfaces are coated with fluorescent colloidal particles. We observed remixing of a phase separated binary fluid as pressure was slowly increased, as well as sudden demixing of a mixed sample on rapid pressure quenching from $101 \mathrm{MPa}$ to $0.1 \mathrm{MPa}$. Our second application was in microbiology. Here, we used pressure cell 2 to obtain high resolution images of the growth of Escherichia coli bacteria at $50 \mathrm{MPa}$. We compared the behaviour of two E. coli strains: the wild-type strain MG1655 and strain BW25113Alon, which is unable to produce the Lon protease enzyme. We observed heterogeneous filamentation of $E$. coli MG1655 at 50MPa, with marked variability among individual cells in the population. In contrast, the lon mutant BW25113 $\Delta$ lon, which is hypersensitive to pressure [60, 63] , showed more uniform filamentation across the population.

We plan to use this pressure cell system for further studies in both colloid science and microbiology. In particular, we are interested in the effects of pressure on the interactions between hydrophobic colloids, as models for protein complexation and aggregation, in further characterising the factors governing $E$. coli filamentation in response to pressure at the single cell level, and in visualising bacterial gene regulatory responses to pressure, using fluorescent reporter proteins. Other applications for this system could include using pressure to trigger phase transitions in complex fluids (as illustrated here for a binary fluid), single cell imaging of microbial killing using short bursts of high pressure and imaging of calcium signalling in mammalian cartilage cells in response to pressure stimuli. Because our system is designed in a modular way, it can easily be augmented with new components as they become necessary for new applications. Components currently under development for use with 
this system include an additional pressure cell capable of achieving even higher pressures, a very high resolution cell for use at lower pressures, a module to allow for injection of liquids into the cell under pressure and a "flow through" module which would allow continuous perfusion of liquid through the pressurised cell.

\section{Acknowledgments}

The authors acknowledge valuable discussions with Doug Bartlett, Gail Ferguson, Andrew Hall and Chiaki
Kato. This work was supported by EPSRC under grant EP/E030173 and by the SoftComp EU Network of Excellence. SLB and EMH were funded by EPSRC studentships. RJA was funded by the Royal Society and by the Royal Society of Edinburgh. We thank NIG Japan for providing the Keio collection and the Collaborative Optical Spectroscopy, Micromanipulation and Imaging Centre (COSMIC) for use of the confocal microscope.
[1] M. I. McMahon and R. J. Nelmes, Chem. Soc. Rev. 35, 943 (2006).

[2] K. D. Pae and S. K. Bhateja, J. Macromolecul. Sci. R. M. C 13, 1 (1975).

[3] S. Deguchi and K. Tsujii, Soft Matter 3, 797 (2007).

[4] L. Smeller, BBA - Protein Struct. M. 1595, 11 (2002).

[5] R. B. Macgregor, BBA - Protein Struct. M. 1595, 266 (2002).

[6] R. Winter, Curr. Opin. Colloid In. 6, 303 (2001).

[7] K. Heremans, Ann. Rev. Biophys. Bioeng. 11, 1 (1982).

[8] J. P. G. Urban, Brit. J. Rheumatol. 33, 901 (1994).

[9] M. B. Seefeldt, M. S. Rosendahl, J. L. Cleland, and L. K. Hesterberg, Curr. Pharm. Biotechnol. 10, 447 (2009).

[10] M. F. San Martin, G. V. Barbosa-Canovas, and B. G. Swanson, Crit. Rev. Food Sci. 42, 627 (2002).

[11] P. Diehl, J. Schauwecker, W. Mittelmeier, and M. Schmitt, Anticancer Res. 28, 3877 (2008).

[12] D. H. Bartlett, in High Pressure Microbiology, edited by C. Michiels, D. H. Bartlett, and A. Aertsen (American Society for Microbiology Press, Washington, D. C., 2008), pp. 195-201.

[13] M. Gross and R. Jaenicker, J. Biotechnol. 126, 11 (2006).

[14] F. Abe, Biosci. Biotech. Bioch. 71, 2347 (2007).

[15] F. Abe, C. Kato, and K. Horikoshi, Trends Microbiol. 7, 447 (1999).

[16] A. Jayamaran, Rev. Mod. Phys. 55, 65 (1983).

[17] P. M. Oger, I. Daniel, and A. Picard, BBA - Prot. Proteom. 1764, 434 (2006).

[18] J.-M. Perrier-Cornet, P.-A. Maréchal, and P. Gervais, J. Biotechnol. 41, 49 (1995).

[19] T. Reck, E. Sautter, W. Dollhopf, and W. Pechhold, Rev. Sci. Instrum. 69, 1823 (1998).

[20] Y. Maeda and M. Koizumi, Rev. Sci. Instrum. 67, 2030 (1996).

[21] M. Hartmann, M. Kreuss, and K. Sommer, Cell. Mol. Biol. 50, 479 (2004).

[22] M. Hartmann, F. Pfeiffer, G. Dornheim, and K. Sommer, Chem-Ing-Tech 75, 1763 (2003).

[23] B. Frey, M. Hartmann, M. Merrmann, R. Meyer-Pittroff, K. Sommer, and G. Bluemelhuber, Microsc. Res. Tech.. 69, 65 (2006).

[24] M. Nishiyama, Y. Kimura, Y. Nishiyama, and M. Terazima, Biophys. J. 96, 1142 (2009).

[25] S. Koyama, T. Miwa, T. Sato, and M. Aizawa, Extremophiles 5, 409 (2001).

[26] E. D. Salmon and G. W. Ellis, J. Cell Biol. 65, 587
(1975).

[27] E. C. Raber, J. A. Dudley, M. Salerno, and P. Urayama, Rev. Sci. Instrum. 77, 096106 (2006).

[28] S. Deguchi and K. Tsujii, Rev. Sci. Instrum. 73, 3938 (2002).

[29] S. Mukai, S. Deguchi, and K. Tsujii, Colloid Surface A 282-283, 483 (2006).

[30] S. R. Besch and P. M. Hogan, Undersea Hyperbar. M. 23, 175 (1996).

[31] S. Mizuno, Am. J. Cell Physiol. 288, C329 (2005).

[32] L. Pagliaro, F. Reitz, and J. Wang, Undersea Hyperbar. M. 22, 171 (1995).

[33] O. Grasset, High Pressure Res. 21, 139 (2001).

[34] R. Shashidar and G. Venkatesh, J. Phys-Paris 40, C3 (1979).

[35] N. S. White, R. J. Errington, M. D. Fricker, and J. L. Wood, J. Microsc. 181, 99 (1996).

[36] F. Meersman, C. M. Dobson, and K. Heremans, Chem. Soc. Rev. 35, 908 (2006).

[37] F. Meersman, J. Wang, Y. Wu, and K. Heremans, Macromolecules 38, 8923 (2005).

[38] G. Hummer, S. Garde, A. E. Garcia, M. E. Paulaitis, and L. R. Pratt, Proc. Natl. Acad. Sci. USA 95, 1552 (1998).

[39] N. Hillson, J. N. Onuchic, and A. E. Garcia, Proc. Natl. Acad. Sci. USA 96, 14848 (1999).

[40] T. Ghosh, A. E. Garcia, and S. Garde, J. Phys. Chem. B 107, 612 (2003).

[41] T. Ghosh, A. E. Garcia, and S. Garde, J. Chem. Phys. 116, 2480 (2002).

[42] R. Vavrin, J. Kohlbrecher, A. Wilk, M. Ratajczyk, M. P. Lettinga, J. Buitenhuis, and G. Meier, J. Chem. Phys. 130, 154903 (2009).

[43] M. P. Lettinga, personal communication.

[44] N. C. Wong and C. M. Knobler, Phys. Rev. Lett. 43, 1733 (1979).

[45] E. M. Herzig, K. A. White, A. B. Schofield, W. C. K. Poon, and P. S. Clegg, Nat. Mater. 6, 966 (2007).

[46] C. Kato, Y. Nogi, and S. Arakawa, in High Pressure Microbiology, edited by C. Michiels, D. H. Bartlett, and A. Aertsen (American Society for Microbiology Press, Washington, D. C., 2008), pp. 203-217.

[47] P. Mañas and B. M. Mackey, Appl. Env. Microbiol. 70, 1545 (2004).

[48] M. Moussa, J.-M. Perrrier-Cornet, and P. Gervais, Appl. Env. Microbiol. 73, 6508 (2007).

[49] T. J. Welch, A. Farewell, F. C. Neidhardt, and D. H. 
Bartlett, J. Bacteriol. 175, 7170 (1993).

[50] A. Aertsen, K. Vanoirbeek, P. de Spiegeleer, J. Sermon, K. Hauben, A. Farewell, T. Nyström, and C. W. Michiels, Appl. Env. Microbiol. 70, 2660 (2004).

[51] A. Aertsen, R. van Houdt, K. Vanoirbeek, and C. W. Michiels, J. Bacteriol. 186, 6133 (2004).

[52] A. Aertsen, P. de Spiegeleer, K. Vanoirbeek, M. Lavilla, and C. W. Michiels, Appl. Env. Microbiol. 71, 2226 (2005).

[53] A. Ishii, T. Sato, M. Wachi, K. Nagai, and C. Kato, Microbiology + 150, 1965 (2004).

[54] A. Aertsen and C. W. Michiels, Crit. Rev. Microbiol. 31, 69 (2005).

[55] I. R. Booth, Int. J. Food Microbiol. 78, 19 (2002).

[56] E. A. Eloe, F. M. Lauro, R. F. Vogel, and D. H. Bartlett, Appl. Env. Microbiol. 74, 6298 (2008).

[57] T. Baba, T. Ara, M. Hasegawa, Y. Takai, Y. Okumura, M. Baba, K. A. Datsenko, M. Tomita, B. L. Wanner, and H. Mori, Mol. Systems Biol. 2, 2006.0008 (2006).

[58] C. E. Zobell and A. B. Cobet, J. Bacteriol. 84, 1228
(1962).

[59] C. E. Zobell and A. B. Cobet, J. Bacteriol. 87, 710 (1964).

[60] A. Aertsen and C. W. Michiels, in High Pressure Microbiology, edited by C. Michiels, D. H. Bartlett, and A. Aertsen (American Society for Microbiology Press, Washington, D. C., 2008), pp. 87-100.

[61] T. Sato, T. Miwa, A. Ishii, C. Kato, M. Wachi, K. Nagai, M. Aizawa, and K. Horikoshi, in Trends in high pressure bioscience and biotechnology, edited by R. Hayashi (Elsevier, Tokyo, 2002), pp. 233-238.

[62] T. Kawarai, M. Wachi, H. Ogino, S. Furukawa, K. Suzuki, H. Ogihara, and M. Yamasaki, Appl. Microbiol. Biotechnol. 64, 255 (2004).

[63] A. Aertsen and C. W. Michiels, Res. Microbiol. 156, 233 (2005).

[64] A. Ishii, T. Oshima, T. Sato, K. Nakasone, H. Mori, and C. Kato, Extremophiles 9, 65 (2005). 